\title{
Gender and Exercise Influence on Tissue Antioxidant Vitamin Status in Rats
}

\author{
Peter M. TiIdus, ${ }^{1,2, *}$ Eric Bombardier, ${ }^{1,2}$ Nick Hidiroglou $^{3}$ \\ and Rene MADERE ${ }^{3}$ \\ ${ }^{1}$ Department of Kinesiology and Physical Education, \\ Wilfrid Laurier University, Waterloo ON, Canada \\ ${ }^{2}$ Department of Kinesiology, University of Waterloo, \\ Waterloo ON, Canada \\ ${ }^{3}$ Nutrition Research Divison, Health Canada, \\ Banting Research Centre, Ottawa ON, Canada
}

(Received May 6, 1999)

\begin{abstract}
Summary Although gender differences in antioxidant status based largely on differing estrogen levels have been postulated, it is not known if other gender based differences in tissue antioxidants exist. This experiment examined whether gender based differences in tissue vitamin $\mathrm{C}$ and vitamin $\mathrm{E}$ concentration exist, and investigated the possibility of gender based differences in indices of tissue oxidative stress following an acute exercise bout. It was determined that female rats had significantly higher levels of vitamin $\mathrm{E}$ in liver and heart tissues than males and that males had significantly more vitamin $\mathrm{C}$ in the plantaris muscle than females. However, female rats also had less liver glutathione than males. Acute exercise resulted in significant and equal tissue oxidative stress in both genders as indicated by tissue glutathione status. With some exceptions, tissue vitamin $\mathrm{C}$ and vitamin $\mathrm{E}$ concentrations were generally unaffected by acute exercise in either gender. Hence, while some gender differences in tissue antioxidant status in rats are evident, these differences do not affect tissue indices of oxidative stress following acute exercise.
\end{abstract}

Key Words vitamin E, vitamin C, glutathione, muscle, heart

It has been suggested that differences in tissue antioxidant protection may exist between genders, which may be due in part to differences in circulating estrogen levels (1-3). These inequalities may influence gender differences in post-exercise indices of tissue oxidative stress, damage and inflammatory response (2-6). However,

* To whom correspondence should be addressed: Department of Kinesiology \& Physical Education, Wilfrid Laurier University, Waterloo ON, Canada N2L 3C5. E-mail: ptiidus@wlu.ca 
potential gender differences in other tissue antioxidants may also exist, and hence, influence tissue antioxidant status. While it appears that human males and females have similar muscle antioxidant enzyme activities (7), there are reported gender based differences in at least some antioxidant enzymes in the liver of ground squirrels (8).

Little is currently known about gender differences in tissue antioxidant vitamin status or the potential for these differences to modify exercise induced oxidative stress. Almost 40 years ago, Edwin et al (9) noted that females tended to have higher tissue vitamin E levels than males. However, these differences were not actually quantified. Vitamin $\mathrm{E}$, a fat-soluble vitamin, and vitamin $\mathrm{C}$, a water-soluble vitamin, both exhibit strong antioxidant properties $(3,10,11)$. The oxidation and loss of both vitamin $\mathrm{E}$ and vitamin $\mathrm{C}$ from tissues following exercise have been interpreted as being indicative of oxidative stress (3, 12-14). In addition, oxidized vitamin $\mathrm{E}$ may be regenerated via interaction with vitamin $\mathrm{C}$ or glutathione. Hence, if gender differences in antioxidant protection, due possibly to differences in estrogen, do exist, post-exercise tissue vitamin $\mathrm{C}$ and/or vitamin $\mathrm{E}$ concentrations may be affected differently in male and female animals. Additionally, if gender based differences in tissue vitamin $\mathrm{E}$ and vitamin $\mathrm{C}$ concentration are evident, they may also contribute to differences in tissue antioxidant protection. This experiment was designed to examine whether gender based differences in tissue vitamin $\mathrm{C}$ and vitamin $\mathrm{E}$ concentration exist, and investigate the possibility of gender based differences in indices of tissue oxidative stress following an acute exercise bout.

\section{MATERIALS AND METHODS}

This study was approved by the University of Waterloo Committee on Animal Care and was performed in accordance to the guiding principles of the Canada Council on Animal Care. As part of a larger study, at approximately 6 wk of age, rats were randomly assigned to either male or female control and exercise groups (10 animals per group). Animals were grouped by gender, 10 per cage in an environmentally controlled room (temp., $22^{\circ} \mathrm{C}$ ) with reverse light/dark cycles. Animals were weighed on a weekly basis. Animals were allowed free access to food and water and fed a standard AIN-93 purified rodent diet containing $75 \mathrm{IU} / \mathrm{kg}$ vitamin $\mathrm{E}$ (15). Since rodents are capable of vitamin $\mathrm{C}$ synthesis in the liver, no vitamin $\mathrm{C}$ was contained in the diet (15). The diets were followed for $8 \mathrm{wk}$ prior to acute exercise and/or sacrifice. All animals were 10-12 wk old and sexually mature prior to the diet phase of the experiments.

Male and female exercise groups were familiarized with the motorized rat treadmill via two, once weekly runs at $15 \mathrm{~m} \cdot \mathrm{min}^{-1}, 12 \%$ grade for $10 \mathrm{~min}$. Immediately prior to sacrifice, exercised animals ran for $60 \mathrm{~min}$ at $21 \mathrm{~m} \cdot \mathrm{min}^{-1}$, $12 \%$ grade. This intensity and duration of acute exercise has been previously demonstrated to induce oxidative stress in the heart and skeletal muscles of rats $(16,17)$. All animals successfully completed the acute exercise protocol. Male and 
female control animals were sacrificed without prior exercise. All animals were anaesthetized with Somnitol $\left(6.0 \mathrm{mg} \cdot \mathrm{kg}^{-1}\right)$ injected interperitoneally, and samples of mixed skeletal muscle (plantaris), liver and heart (ventricles) were quickly removed. Tissue samples were thoroughly rinsed in physiological saline, blotted to remove blood, immediately frozen in liquid nitrogen and stored at $-80^{\circ} \mathrm{C}$ until analysis.

Tissue vitamin $\mathrm{C}$ concentrations as reduced ascorbate (RA), dehydroascorbate (DHA) and total ascorbate (TA) were determined by HPLC (18); vitamin E concentrations as $\alpha$-tocopherol and $\gamma$-tocopherol were determined by HPLC (19); and glutathione status as reduced (GSH), oxidized (GSSG) and total glutathione were also determined by HPLC (20) as previously described (7). All tissue concentrations were expressed as $\mu \mathrm{g} \cdot \mathrm{g}$ tissue wet weight ${ }^{-1}$.

Data were analyzed using two-way analysis of variance (ANOVA) with Student-Neuman-Keuls post-hoc tests. Significance was defined a priori as $p<0.05$.

\section{RESULTS}

Some of the data on male animals has been previously reported in another context as part of a larger study (21). Animal weights $(\mathrm{g})$ at the time of sacrifice were as follows $(\bar{x} \pm \mathrm{SD})$ : male control, $480.4 \pm 34.7$; male exercise, $412.7 \pm 20.5$; female control $343.9 \pm 26.4$; and female exercise $307.7 \pm 24.8$. Male animals were significantly $(p<0.01)$ heavier than females and control animals were significantly $(p<0.05)$ heavier than exercised animals.

Tissue vitamin $\mathrm{C}$ concentrations are depicted in Fig. 1. In the plantaris muscle, vitamin $\mathrm{C}$ existed primarily in the DHA form, while RA was the predominant form in the liver. Vitamin $C$ in the heart tissue consisted of approximately equal proportions of RA and DHA forms. Female rats had significantly $(p<0.05)$ less plantaris vitamin C (RA, DHA, TA) than male rats. However, there were no gender differences in vitamin $\mathrm{C}$ levels in the liver or heart. Acute exercise significantly $(p<0.01)$ diminished total vitamin $\mathrm{C}$ concentration in the heart, primarily due to loss of the RA form in both male and female animals, with no difference between genders. Exercise did not affect vitamin $\mathrm{C}$ concentrations in the liver or plantaris muscle in either male or female animals.

Tissue vitamin $\mathrm{E}$ concentrations are depicted in Fig. 2. The vast majority of vitamin $\mathrm{E}$ in the plantaris, heart and liver was in the form of $\alpha$-tocopherol. Female rats had significantly $(p<0.05)$ higher vitamin $\mathrm{E}$ concentrations (as $\alpha$ - and $\gamma$-tocopherol) in the liver and heart tissues than male rats, while there were no gender differences in vitamin $\mathrm{E}$ level in the plantaris muscle. Acute exercise did not affect vitamin E concentrations in the liver or heart tissue of either gender. However, exercise induced significantly $(p<0.01)$ elevated levels of $\alpha$ - and $\gamma$-tocopherol in the plantaris muscle of female rats while only $\gamma$-tocopherol was significantly elevated in the plantaris muscle of male rats following exercise.

Liver and plantaris muscle glutathione status (as GSH, GSSG and total 

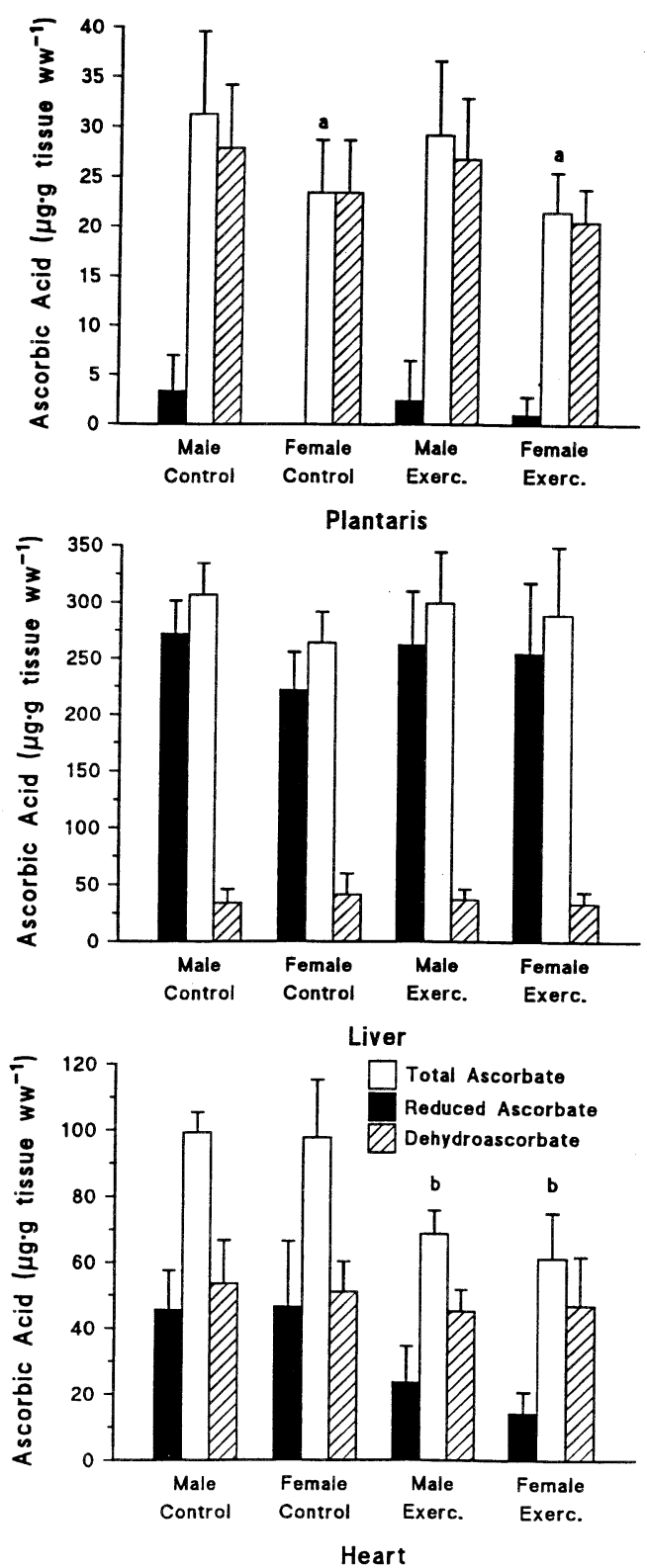

Fig. 1. Tissue vitamin $\mathrm{C}$ in the plantaris, liver and heart of male and female rats at rest or immediately following acute running exercise. Mean \pm SD. $n=10$ per group. ${ }^{a}$ Significant main effect of gender $(p<0.01)$, female control and exercised animals $<$ male control and exercised animals. ${ }^{\mathrm{b}}$ Significant main effect of exercise $(p<0.01)$ exercised male and female animals $<$ unexercised male and female control animals. 

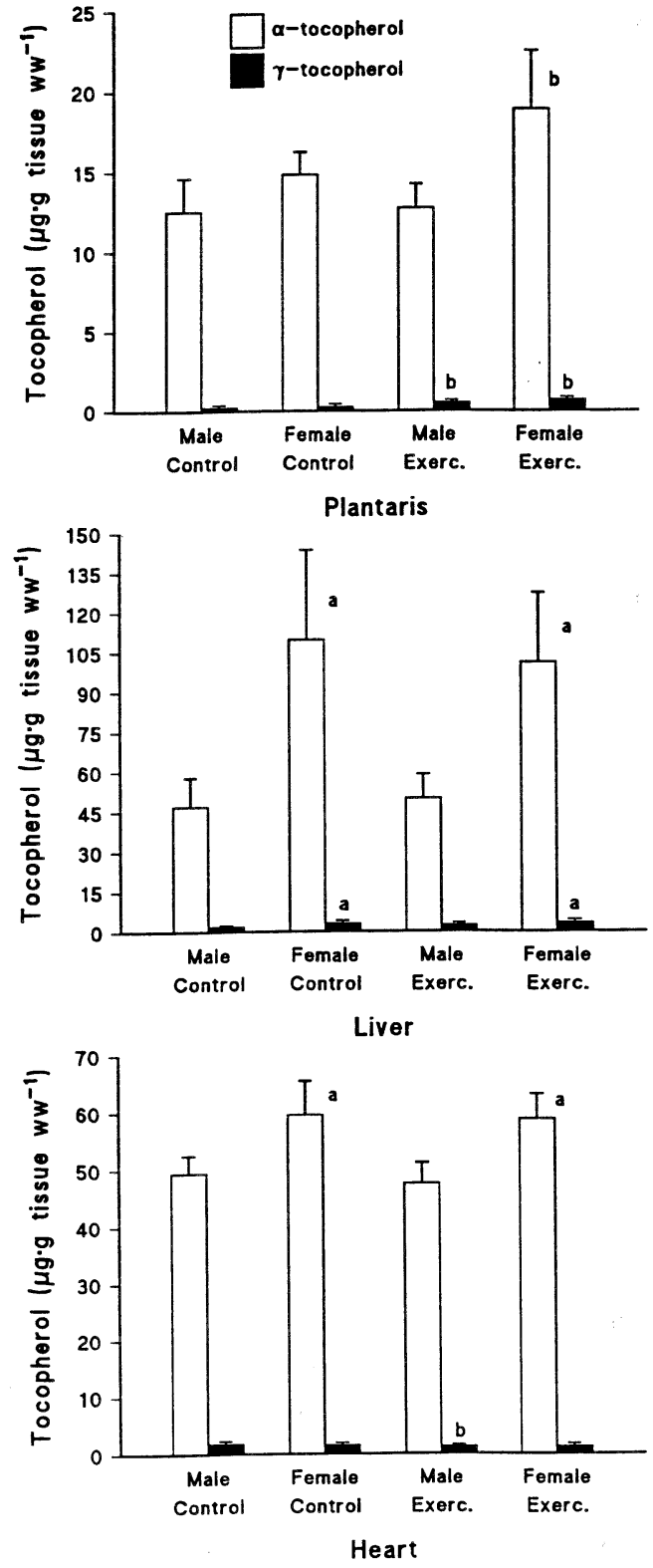

Fig. 2. Tissue vitamin $\mathrm{E}$ status in the plantaris, liver and heart of male and female rats at rest or immediately following acute running exercise. Mean \pm SD. $n=10$ per group. ${ }^{a}$ Significant main effect of gender $(p<0.01)$, female control and exercised animals $>$ male control and exercised animals. ${ }^{\mathrm{b}}$ Significant main effect of exercise $(p<0.01)$, exercised male and female animals $>$ unexercised male and female control animals. 
Table 1. Glutathione status in liver and plantaris tissues of male and female control and acutely exercised rats.

\begin{tabular}{cllcc}
\hline Tissue & Group & GSH & GSSG & Total glut. \\
\hline Liver $^{\mathrm{a}}$ & Male control & $8.40 \pm 1.26$ & $1.95 \pm 0.49$ & $10.35 \pm 1.32$ \\
& Female control & $5.06 \pm 1.84^{\mathrm{c}}$ & $2.49 \pm 1.10$ & $7.55 \pm 1.26^{\mathrm{c}}$ \\
& Male exercise & $4.59 \pm 0.80^{\mathrm{d}}$ & $2.85 \pm 0.37$ & $7.44 \pm 0.87^{\mathrm{d}}$ \\
& Female exercise & $3.01 \pm 2.10^{\mathrm{d}}$ & $1.61 \pm 0.35$ & $4.63 \pm 2.02^{\mathrm{d}}$ \\
Plantaris $^{\mathrm{b}}$ & Male control & $2.11 \pm 0.46$ & $0.07 \pm 0.01$ & $2.26 \pm 0.46$ \\
& Female control & $2.31 \pm 0.43$ & $0.10 \pm 0.02$ & $2.41 \pm 0.46$ \\
& Male exercise & $1.74 \pm 0.73$ & $0.09 \pm 0.02$ & $1.83 \pm 0.46$ \\
& Female exercise & $1.62 \pm 0.27^{\mathrm{d}}$ & $0.09 \pm 0.01$ & $1.80 \pm 0.28^{\mathrm{d}}$ \\
\hline
\end{tabular}

Values are mean $\pm \mathrm{SD} \mu \mathrm{g} / \mathrm{g}$ tissue wet weight. GSH, reduced glutathione; GSSG, oxidized glutathione.

a Significant $(p<0.01)$ main effects of gender on GSH and total glutathione (male $>$ female) and exercise (control $>$ exercise $p<0.01$ ).

${ }^{\mathrm{b}}$ Significant main effect on GSH and total glutathione of exercise (control $>$ exercise $p<0.01)$.

${ }^{\mathrm{c}}$ Significantly $(p<0.05)$ lower than male control group.

${ }^{\mathrm{d}}$ Significantly $(p<0.05)$ lower than (unexercised) control group.

glutathione) are depicted in Table 1. Heart glutathione status was not determined. Female animals had significantly $(p<0.05)$ lower hepatic levels of total glutathione and GSH than male animals. No gender differences in glutathione status were evident in the plantaris muscle. Acute exercise induced a significant $(p<0.05)$ loss of total glutathione due primarily to GSH loss in both the liver and plantaris muscle of female and male animals.

\section{DISCUSSION}

This study demonstrated that gender differences in certain antioxidant vitamins are evident in some tissues of rats. In particular, female rats had over twice as much liver vitamin E stores as their male counterparts as well as significantly higher vitamin $\mathrm{E}$ levels in the heart. Conversely, male rats had slightly more vitamin $\mathrm{C}$ stores in the plantaris muscle than females. Chen et al (22) had also previously noted that female rats tended to have higher $\alpha$-tocopherol levels than male rats but did not report values for other tissues or different forms of tocopherol.

The liver is thought to be a net exporter of vitamin $\mathrm{E}$ to other tissues during times of oxidative stress $(13,23)$. If so, female animals would have a significantly larger liver reserve of vitamin $\mathrm{E}$ (in both $\alpha$-and $\gamma$-tocopherol forms) to assist in mitigating oxidative stress in other tissues. However, this female advantage in liver vitamin E concentration may be partially offset by the lower level of liver GSH. Liver is also a net exporter of GSH to other tissues during oxidative stress $(24,25)$. 
Hence, any potential gender based advantage in protection afforded by the higher levels of liver vitamin $\mathrm{E}$ in female rats may be negated by, or perhaps exist in compensation for, the lower level of liver GSH. GSH is synthesized in the liver and exported to other tissues such as muscle during times of oxidative stress $(24,25)$. The liver also functions as the primary rapid turnover store of vitamin E (26). The mechanisms associated with gender based differences in liver and heart tissue vitamin E stores are not known but may be mediated by factors related to its absorption and transport (22). It is conceivable that estrogen, which is known to affect fat and lipid metabolism (27), may play a role. However, our previous study involving supra-physiological levels of estrogen administration to male and female guinea pigs did not find an effect on tissue vitamin E levels (28). Other possibilities include potential gender differences in tocopherol binding or transfering protein levels.

Tissue vitamin $\mathrm{C}$ concentration was lower in the plantaris muscle of female animals than in male animals, but no gender differences existed in the liver or heart vitamin $\mathrm{C}$ content. We have previously demonstrated that estrogen administration at supra-normal levels will diminish tissue vitamin $\mathrm{C}$ content in male rats and both male and female guinea pigs $(20,21)$. It is possible that the gender difference in plantaris vitamin $\mathrm{C}$ content could be influenced by differing levels of estrogen between male and female rats. However, a lack of difference in liver or heart vitamin $\mathrm{C}$ content argues against a general negative effect of estrogen on tissue vitamin $\mathrm{C}$ content in normal female rats.

Unlike many other tissues, we found in this and in a previous study (21) that the plantaris muscle contains the majority of vitamin C in DHA form. Whether this is unique to the plantaris muscle or generally found in all skeletal muscles cannot be ascertained from this study. Nor is it yet known whether this is due to any differences in muscle levels of dehydroascorbate reductase.

Acute exercise generally lowered the GSH and total glutathione content of both liver and plantaris muscle in male and female rats. Loss of tissue GSH as a consequence of acute exercise is indicative of oxidative stress $(24,25)$. Hence, these findings support previous reports which suggested the intensity and duration of exercise employed in this study result in increased free radical generation, peroxidative tissue and lipid damage and oxidative stress $(16,17)$.

Previous studies are ambiguous about whether exercise induced oxidative stress may induce loss of tissue antioxidant vitamin content $(10,12,13,25,29)$. In the present study, acute exercise did not diminish vitamin $\mathrm{E}$ content in the heart, liver or plantatis muscle of either gender. In fact, both $\alpha$ - and $\gamma$-tocopherol levels were elevated post-exercise in the plantaris muscle of female rats while $\gamma$-tocopherol alone was elevated post-exercise in male rats. This suggests that the oxidative stress experienced by the plantaris muscle during the exercise protocol may have resulted in increased vitamin $E$ transport to the muscle from liver stores. It may be that the higher plantaris vitamin E levels seen in female rats following exercise may have been related to their higher liver vitamin $\mathrm{E}$ content.

Plantaris and liver vitamin $\mathrm{C}$ content were unaffected by exercise in either 
gender. However, vitamin $\mathrm{C}$ levels were significantly lower following exercise in the heart muscle of both male and female rats. To our knowledge this is the first report of exercise induced loss of vitamin $\mathrm{C}$ from rat heart. It is uncertain why the heart would lose vitamin $\mathrm{C}$ consequent to exercise while liver and plantaris muscle remain unaffected. While several studies have suggested that heart muscle also experiences oxidative stress during exercise, the degree of oxidative stress is generally less than or equal to that seen in skeletal muscle $(25,30)$. Keith $(10,12)$ has suggested that while the mechanisms are not yet fully explained, exercise may affect the vitamin $\mathrm{C}$ metabolism in at least some tissues of rats and guinea pigs. Why the vitamin $\mathrm{C}$ content of some tissues are affected by exercise while others are not is unknown.

In addition to differences in antioxidant vitamin status, there are gender differences in circulating estrogen levels which also may influence antioxidant status $(2,3,30)$. Nevertheless, no systematic gender differences in tissue post-exercise oxidative stress were noted insofar as this can be ascertained from changes in tissue glutathione status and tissue vitamin $\mathrm{E}$ and vitamin $\mathrm{C}$ concentrations. It may be that gender differences in antioxidant status in rats may not be of sufficient magnitude to significantly influence overt manifestations of oxidative stress as induced by sub-maximal exercise.

In summary, this study demonstrated that gender based differences in vitamin $\mathrm{E}$ and vitamin $\mathrm{C}$ status do exist in some tissues of the rat. Although both vitamin $\mathrm{E}$ and vitamin $\mathrm{C}$ are antioxidants, these and other possible gender based differences in antioxidant status do not influence indices of tissue oxidative stress differently between genders following acute sub-maximal exercise. In addition, acute exercise as employed in this study did not result in a significant reduction in antioxidant vitamin status in most, but not all tissues of both male and female rats.

This study was supported by a Natural Sciences and Engineering Council of Canada (NSERC) research grant to Peter M. Tiidus.

\section{REFERENCES}

1) Bär PR, Reijneveld JC, Wokke JH, Jacobs S, Bootsma AL. 1997. Muscle damage induced by exercise: nature, prevention and repair. In: Muscle Damage (Salmons S, ed.), p 1-27. Oxford University Press, Oxford, UK.

2) Amelink GJ, van der Wal WA, van Asbeck BS, Bär PR. 1991. Exercise-induced muscle damage in the rat: the effect of vitamin E deficiency. Pflügers Arch 419: 304-309.

3) Tiidus PM. 1995. Can estrogens diminish exercise induced muscle damage? Can J Appl Physiol 20: 26-38.

4) Ebbeling CB, Clarkson PM. 1989. Exercise-induced muscle damage and adaptation. Sports Med 7: 207-234.

5) Paroo Z, Tiidus PM, Noble EG. 1999. Estrogen attenuates HSP 72 expression in acutely exercised male rodents. Eur J Appl Physiol 80: 180-184.

6) Tiidus PM, Bombardier E. 1999. Estrogen attenuates post-exercise myeloperoxidase activity in skeletal muscle of male rats. Acta Physiol Scand 166: 85-90.

7) Tiidus PM, Pushkarenko J, Houston ME. 1996. Lack of antioxidant adaptation to 
short-term aerobic training in human muscle. Am J Physiol 271: R832-R836.

8) Buzadzic B, Spasic M, Saicic Z, Radojicic R, Halliwell B, Petrovic VM. 1990. Antioxidant defenses in the ground squirrel: a comparison with the rat. Free Rad Biol Med 9: 401-406.

9) Edwin EE, Diplock AT, Bunyan J, Green J. 1961. The distribution of vitamin E in the rat and the effect of $\alpha$-tocopherol and dietary selenium on ubiquinone and ubichromenol in tissues. Biochem J 79: 91-104.

10) Keith RE. 1989. Vitamins in sport and exercise. In: Nutrition in Exercise and Sport (Hickson JF, Wolinsky I, eds), p 233-253. CRC Press, Boca Raton, FL.

11) Burton GW, Ingold KU. 1989. Vitamin $\mathrm{E}$ as an in vivo and in vitro antioxidant. Ann NY Acad Sci 570: 7-22.

12) Keith RE, Pomerance GM. 1995. Exercise and tissue ascorbic acid content in guinea pigs. Nutr Res 15: 423-428.

13) Packer L, Almada AL, Rothfuss LM, Wilson DS. 1989. Modulation of tissue vitamin E levels by physical activity. Ann NY Acad Sci 570: 311-321.

14) Roginsky VA, Stegmann HB. 1994. Ascorbyl radical as natural indicator of oxidative stress: quantitative regularities. Free Rad Biol Med 17: 93-103.

15) Reeves PG, Nielson FH, Fahey GC. 1993. AIN-93 purified diets for laboratory rodents: Final report of the American Institute of Nutrition Ad Hoc Writing Committee on the reformulation of the AIN-76A rodent diet. J Nutr 123: 1939-1951.

16) Goldfarb AH, McIntosh MK, Boyer BT. 1996. Vitamin E attenuates myocardial oxidative stress induced by DHEA in rested and exercised rats. $J$ Appl Physiol 80: 486-490.

17) Goldfarb AH, McIntosh MK, Boyer BT, Fatouros J. 1994.Vitamin E effects on indexes of lipid peroxidation in muscle from DHEA-treated and exercised rats. $J$ Appl Physiol 76: 1630-1635.

18) Behrens WA, Madere R. 1987. A highly sensitive high performance liquid chromatography method for the estimation of ascorbic acid and dehydroascorbic acid in tissue, biological fluids and foods. Anal Biochem 165: 102-107.

19) Thompson J, Hatina G. 1979. Determination of tocopherols and tocotrienols in foods and tissues by high performance liquid chromatography. $J$ Liquid Chromatogr 2: 327-344.

20) Fariss MW, Reid DJ. 1987. High-performance liquid chromatography of thiols and disulfides; dinitrophenol derivatives. Methods Enzymol 143: 101-109.

21) Tiidus PM, Bombardier E, Hidiroglou N, Madere R. 1998. Estrogen administration, post-exercise tissue oxidative stress and vitamin C status in male rats. Can J Physiol Pharmacol 76: 952-960.

22) Chen HW, Cook LR, Hendrick S. 1992. Gender and dietary fat affect $\alpha$-tocopherol status in F344/N rats. Lipids 27: 844-846.

23) Elsayed NB. 1989. Mobilization of vitamin E to the lung under oxidative stress. Ann NY Acad Sci 570: 439-440.

24) Sen CK, Marin E, Kretzschmar M, Hänninen O. 1992. Skeletal muscle and liver glutathione homeostasis in response to training, exercise and immobilization. $J$ Appl Physiol 73: 1265-1272.

25) Ji LL. 1995. Exercise and oxidative stress: role of the cellular antioxidant systems. In Exercise and Sport Sciences Reviews (Holloszy JO, ed), Vol 23, p 135-166. Williams \& Wilkins, Baltimore.

26) Sokol RJ. 1989. Vitamin E and neurological function in man. Free Rad Biol Med 6: 189-207. 
27) Kendrick ZF, Steffen C, Rumsey W, Goldberg D. 1987. Effect of estradiol on tissue glycogen metabolism in oophorectomized rats. $J$ Appl Physiol 67: 492-496.

28) Tiidus PM, Bombardier E, Scaman C, Sham P, Hidiroglou N, Madere R. 1999. Vitamin $\mathrm{C}$ and vitamin $\mathrm{E}$ status in guinea pig tissues following estrogen administration. Nutr Res 19: 773-782.

29) Tiidus PM, Behrens WA, Madere R, Kim JJ, Houston ME. 1993. Effects of vitamin E status and exercise training on tissue lipid peroxidation based on two methods of assessment. Nutr Res 13: 219-224.

30) Tiidus PM, Behrens WA, Madere R, Houston ME. 1993. Muscle vitamin E levels following acute submaximal exercise in female rats. Acta Physiol Scand 147: 249-250. 